\title{
Adverse Drug Reactions in Japanese Patients with End-Stage Heart Failure Receiving Continuous Morphine Infusion: A Single-Center Retrospective Cohort Study
}

\author{
Masayuki Gotou $^{1} \cdot$ Atsushi Suzuki $^{1} \cdot$ Tsuyoshi Shiga $^{1,2}{ }^{(D} \cdot$ Rumi Wakabayashi $^{3} \cdot$ Mayui Nakazawa $^{1} \cdot$ Noriko Kikuchi $^{1}$. \\ Nobuhisa Hagiwara ${ }^{1}$
}

Accepted: 9 September 2021 / Published online: 6 October 2021

(c) The Author(s) 2021

\begin{abstract}
Background Opioids have been reported to be effective for refractory dyspnea in patients with advanced heart failure (HF) in the palliative care setting.

Objective The aim of this study was to evaluate the incidence of adverse drug reactions (ADRs) and their relationship with morphine dose/duration or renal insufficiency in patients with end-stage HF receiving continuous morphine infusion.

Methods We retrospectively studied 38 patients with end-stage HF receiving continuous intravenous or subcutaneous morphine infusion for the relief of breathlessness between 2014 and 2019 (mean age 78 years). The endpoints were nausea/ vomiting, respiratory depression, and drowsiness, which are common morphine-related ADRs.

Results Of 38 patients with end-stage HF receiving continuous intravenous/subcutaneous morphine infusion, 14 (37\%) experienced ADRs. The median estimated glomerular filtration rate (eGFR) was lower in patients with than in those without ADRs (16 [range 9-48] vs. 41 [range 8-133], respectively; $p=0.011)$. The ADRs with the highest incidence were drowsiness ( $n=13)$, nausea/vomiting $(n=5)$, and respiratory depression $(n=3)$. There were no differences in the maintenance dose or duration of morphine administration between patients with and without ADRs. A baseline eGFR of $32 \mathrm{~mL} / \mathrm{min} / 1.73 \mathrm{~m}{ }^{2}$ was a good cutoff value for ADR prediction (sensitivity $86 \%$, specificity $96 \%$ ). A baseline eGFR $<32 \mathrm{~mL} / \mathrm{min} / 1.73 \mathrm{~m}^{2}$ was significantly associated with the occurrence of morphine-related ADRs (odds ratio 6.63, 95\% confidence interval 1.19-37.01). Conclusions Our results showed that $37 \%$ of patients with end-stage HF receiving continuous intravenous/subcutaneous morphine infusion experienced ADRs, especially drowsiness. Patients with eGFR $<32 \mathrm{~mL} / \mathrm{min} / 1.73 \mathrm{~m}^{2}$ were likely to experience morphine-related ADRs.
\end{abstract}

Tsuyoshi Shiga

shiga@jikei.ac.jp

1 Department of Cardiology, Tokyo Women's Medical

University, Tokyo, Japan

2 Department of Clinical Pharmacology and Therapeutics, The Jikei University School of Medicine, 3-25-8 Nishi-shinbashi, Minato-ku, Tokyo 105-8461, Japan

3 Department of Nursing, Tokyo Women's Medical University Hospital, Tokyo, Japan 


\section{Key Points}

Opioids improve abnormal ventilation patterns in patients with heart failure (HF), resulting in the relief of dyspnea and pain.

Continuous intravenous/subcutaneous morphine infusion is used in the palliative care setting for patients with endstage HF when the oral route has been unreliable. The maintenance dose (median $0.4 \mathrm{mg} / \mathrm{h}$ ) is lower than that in patients with cancer-related pain.

More than $30 \%$ of patients with end-stage $\mathrm{HF}$ receiving continuous intravenous/subcutaneous morphine infusion experience adverse drug reactions (ADRs), especially drowsiness.

A baseline estimated glomerular filtration rate $<32 \mathrm{~mL} /$ $\mathrm{min} / 1.73 \mathrm{~m}^{2}$ was significantly associated with the occurrence of morphine-related ADRs.

\section{Introduction}

End-stage heart failure (HF) is defined as the presence of progressive or persistent severe signs and symptoms of HF despite optimal medical or nonpharmacologic treatments [1, 2]. Dyspnea, angina, and malaise are frequently observed in patients with end-stage HF [3]. Hospice care, including the administration of opioids, is recommended as an appropriate means of relieving symptoms [4]. Opioids have the effect of improving abnormal ventilation patterns in patients with $\mathrm{HF}$, resulting in the relief of dyspnea and pain. Oral opioids have been reported to be effective in both the long term and the short term for refractory dyspnea in patients with chronic HF [5]. Continuous intravenous/subcutaneous morphine infusion is also used in the palliative care setting for patients with end-stage HF [6]. However, the dose and duration of continuous morphine infusion have not been established for refractory dyspnea and pain relief in patients with end-stage HF.

The major adverse drug reactions (ADRs) associated with morphine, such as nausea/vomiting, constipation, respiratory depression, and drowsiness occur regardless of the dose $[6,7]$. Morphine is metabolized in the liver to morphine-3-glucuronide and morphine-6-glucuronide (M6G), which is excreted by the kidneys. M6G is an active metabolite, and renal dysfunction increases its blood levels and promotes the occurrence of morphine-related ADRs [8]. Renal dysfunction is observed in approximately half of patients with HF [9], indicating possible drug elimination impairment. However, there have been few reports about the ADRs associated with continuous morphine infusion in Japanese patients with end-stage HF. We aimed to retrospectively evaluate the incidence of morphine-related ADRs and their relationship with morphine dose/duration and renal insufficiency in patients with end-stage HF receiving continuous morphine infusions.

\section{Methods}

\subsection{Patients}

We conducted a retrospective cohort study involving 38 consecutive patients with end-stage HF who received continuous intravenous/subcutaneous morphine infusions at Tokyo Women's Medical University Hospital between April 2014 and July 2019. To identify patients who had received intravenous or subcutaneous morphine, we first searched the automated inpatient databases. We then examined patient electronic medical records to confirm that the identified patients had a diagnosis of end-stage HF. End-stage HF was defined as the presence of progressive or persistent severe signs and symptoms of HF despite optimal medical or nonpharmacologic treatments [1, 2]. We excluded patients for whom morphine was administered because of indications other than HF symptoms, patients on hemodialysis, patients with insufficient data, and patients treated with a morphine bolus (Fig. 1). The protocol was approved by the Institutional Review Board of Tokyo Women's Medical University.

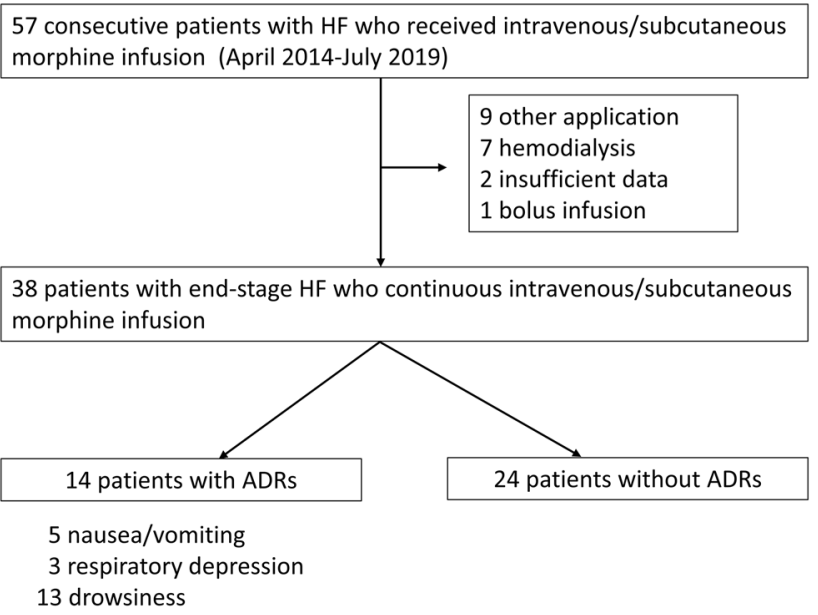

Fig. 1 Flow diagram of the selection of the patients for this study. $A D R s$ adverse drug reactions, $H F$ heart failure 


\subsection{Data Collection}

Data on patient age, sex, underlying diseases, and HF status were obtained from electronic medical records and laboratory data. The estimated glomerular filtration rate (eGFR) was calculated using the Japanese version of the Modification of Diet in Renal Disease formula [10]. Echocardiography was performed during index hospitalization, and the left ventricular ejection fraction was calculated using the biplane Simpson method. We also collected the following patient information regarding morphine usage: dose and duration, administration route during continuous infusion, and common adverse events after the initiation of morphine based on the descriptions in the medical charts. Activity level was evaluated using the Common Terminology Criteria for Adverse Events (CTCAE) version 5.0 from the Japanese Cooperative Oncology Group (JCOG) version [11].

\subsection{Outcomes}

The primary outcomes were common morphine-related ADRs, which were validated through a review of the medical records performed by two investigators (MG and AS). We selected nausea/vomiting, respiratory depression, and drowsiness as common morphine-related ADRs from among the ADRs that were reported to be associated with continuous morphine infusion in the cancer pain management setting [12-14], as these were objective symptoms that could be retrospectively assessed based on medical charts and nursing records. We considered these symptoms, of grade 3 or higher according to the CTCAE v5.0 JCOG [11], to be ADRs. Respiratory depression was defined as hypoxemia (oxygen saturation $<90 \%$ ) with decreased respiratory rate ( $\leq 8$ breaths per minute), and drowsiness was defined as a state of feeling abnormally sleepy or falling asleep at inappropriate times (during the day) without new or worsening of other symptoms and signs of HF.

\subsection{Statistical Analysis}

Summary data are presented as numbers of patients or as medians and ranges. Demographic and clinical data were compared between groups using Student's $t$ tests and Mann-Whitney $U$ tests. Categorical variables were subjected to chi-squared analysis. To assess the predictive value of the eGFR for ADRs, receiver operating characteristic (ROC) curve analysis was used. The optimal cutoff value, sensitivity, and specificity were determined by the Youden index. To evaluate the relationship between this eGFR cutoff value and ADRs, logistic regression analysis was used and adjusted for well-known factors: age, female sex, and body weight $[15,16]$.

A $p$ value $<0.05$ was considered to indicate a statistically significant difference. Data analyses were performed using SPSS (Statistical Package for the Social Sciences) statistical software (version 11.01, SPSS Inc., Chicago, IL, USA).

\section{Results}

Of the 38 patients who received continuous intravenous/subcutaneous morphine infusions, 14 (37\%) experienced grade 3 or higher morphine-related ADRs. The characteristics of patients with and without morphine-related ADRs are shown in Table 1. The eGFR was lower in patients with ADRs than in patients without ADRs, and patients with ADRs did not use any angiotensin-converting enzyme (ACE) inhibitors/ angiotensin II receptor blockers (ARBs). There was no significant difference in other background clinical characteristics between the two groups.

Regarding adverse events, the most frequent event was drowsiness, followed by nausea/vomiting (Fig. 1). Table 2 compares the maintenance dose and duration of continuous morphine administration and renal function between patients who did and did not experience ADRs overall and individually. There were no differences in the maintenance dose and duration of morphine administration between patients who did and did not experience ADRs. However, the eGFR was lower in patients who experienced morphine-related ADRs, especially drowsiness, than in patients who did not. Among three patients who experienced respiratory depression, one patient reduced the morphine dosage from 0.4 to $0.2 \mathrm{mg} / \mathrm{h}$ and one patient discontinued morphine infusion $(0.4 \mathrm{mg} / \mathrm{h})$.

The area under the ROC curve for eGFR was 0.75 (95\% confidence interval $[\mathrm{CI}] 0.58-0.88$ ), and the optimal cutoff value calculated from the ROC analysis for the prediction of morphine-related ADRs was $32 \mathrm{~mL} / \mathrm{min} / 1.73 \mathrm{~m}^{2}$ (sensitivity $86 \%$, specificity $96 \%$ ). A regression model adjusted for age, sex, and body weight showed that an eGFR $<32 \mathrm{~mL} /$ $\mathrm{min} / 1.73 \mathrm{~m}^{2}$ was significantly associated with ADRs (odds ratio 6.63; 95\% CI 1.19-37.01). The incidence of ADRs was higher in patients with an eGFR $<32 \mathrm{~mL} / \mathrm{min} / 1.73 \mathrm{~m}^{2}$ than in patients with an eGFR $\geq 32 \mathrm{~mL} / \mathrm{min} / 1.73 \mathrm{~m}^{2}(11 / 21 \mathrm{vs}$. $3 / 17$, respectively; $p=0.03$ ). In patients with an eGFR $<32$ $\mathrm{mL} / \mathrm{min} / 1.73 \mathrm{~m}^{2}$, ADRs were observed even at low maintenance doses (Fig. 2).

\section{Discussion}

Our study in patients with end-stage HF receiving continuous morphine infusions revealed the following findings: (1) $37 \%$ of the patients experienced grade 3 or higher ADRs; 
Table 1 Patient characteristics

\begin{tabular}{|c|c|c|c|c|}
\hline Characteristics & Total $(n=38)$ & With ADRs $(n=14)$ & Without ADRs $(n=24)$ & $p$ value \\
\hline Age (years) & $78(43-102)$ & $73(61-91)$ & $79(43-102)$ & 0.36 \\
\hline Male & $23(60)$ & $10(71)$ & $13(54)$ & 0.28 \\
\hline Body weight (kg) & $52(33-77)$ & $55(33-77)$ & $50(33-75)$ & 0.19 \\
\hline Cardiovascular disease & & & & 0.20 \\
\hline Ischemic heart disease & $8(21)$ & $1(7)$ & $7(29)$ & \\
\hline Nonischemic cardiomyopathy & $12(32)$ & $7(50)$ & $5(21)$ & \\
\hline Valvular heart disease & $7(18)$ & $2(14)$ & $5(21)$ & \\
\hline Others & $11(29)$ & $4(29)$ & $7(29)$ & \\
\hline NYHA functional class III/IV & $33(87)$ & $12(86)$ & $21(88)$ & 0.88 \\
\hline LVEF (\%) & $36(13-59)$ & $36(25-59)$ & $38(13-58)$ & 0.74 \\
\hline Albumin (g/dL) & $3.0(1.3-4.6)$ & $3.0(2.1-3.7)$ & $2.9(1.3-4.6)$ & 0.90 \\
\hline Total bilirubin (mg/dL) & $1.2(0.4-5.8)$ & $1.1(0.4-5.8)$ & $1.2(0.5-2.9)$ & 0.27 \\
\hline AST (IU/L) & $33(12-2641)$ & $33(12-368)$ & $37(15-2641)$ & 0.27 \\
\hline $\operatorname{ALT}(\mathrm{IU} / \mathrm{L})$ & $21(3-2248)$ & $14(3-452)$ & $28(6-2248)$ & 0.38 \\
\hline GGT (IU/L) & $76(21-611)$ & $62(36-256)$ & $97(21-611)$ & 0.53 \\
\hline $\mathrm{eGFR}\left(\mathrm{mL} / \mathrm{min} / 1.73 \mathrm{~m}^{2}\right)$ & $27(8-133)$ & $16(9-48)$ & $41(8-133)$ & 0.01 \\
\hline Plasma BNP (pg/mL) & $897(215-4792)$ & $1065(253-4792)$ & $820(215-2746)$ & 0.61 \\
\hline \multicolumn{5}{|l|}{ Medications } \\
\hline ACE inhibitors or ARBs & $7(18)$ & 0 & $7(29)$ & 0.03 \\
\hline$\beta$-blockers & $16(42)$ & $5(36)$ & $11(46)$ & 0.54 \\
\hline Diuretics & $34(89)$ & $13(93)$ & $21(88)$ & 0.60 \\
\hline Oral anticoagulants & 13 & $4(34)$ & $9(38)$ & 0.58 \\
\hline Intravenous inotropes & $27(71)$ & $10(71)$ & $17(71)$ & 0.97 \\
\hline Intravenous vasodilator & $7(18)$ & $2(14)$ & $5(21)$ & 0.62 \\
\hline Use of NPPV & $9(24)$ & $2(14)$ & $7(29)$ & 0.30 \\
\hline Use of IABP & $2(5)$ & $1(7)$ & $1(4)$ & 0.69 \\
\hline \multicolumn{5}{|l|}{ Morphine } \\
\hline Administration route & & & & 0.11 \\
\hline Intravenous & $34(89)$ & $14(100)$ & $20(83)$ & \\
\hline Subcutaneous & $4(11)$ & 0 & $4(17)$ & \\
\hline Initial dose (mg/h) & $0.4(0.1-0.4)$ & $0.4(0.1-0.4)$ & $0.4(0.2-0.4)$ & 0.61 \\
\hline Maintenance dose (mg/h) & $0.4(0.1-1.6)$ & $0.4(0.2-1.6)$ & $0.4(0.1-1.3)$ & 0.89 \\
\hline Duration (days) & $4(1-52)$ & $4(1-22)$ & $5(1-52)$ & 0.62 \\
\hline
\end{tabular}

Data are presented as $\mathrm{n}(\%)$ or median (range)

$A C E$ angiotensin-converting enzyme, $A D R$ adverse drug reaction, $A L T$ alanine transaminase, $A R B$ angiotensin II receptor blocker, $A S T$ aspartate transaminase, $B N P$ B-type natriuretic peptide, $e G F R$ estimated glomerular filtration rate, $G G T$ gamma-glutamyl transpeptidase, $I A B P$ intra-aortic balloon pumping, $L V E F$ left ventricular ejection fraction, $N P P V$ noninvasive positive pressure ventilation, NYHA New York Heart Association

(2) the eGFR was lower in patients with than without ADRs; (3) the incidence of drowsiness was the highest among the ADRs and was related to a low baseline eGFR but not to the dose or duration of continuous morphine infusion; and (4) a baseline eGFR $<32 \mathrm{~mL} / \mathrm{min} / 1.73 \mathrm{~m}^{2}$ was significantly associated with the occurrence of morphine-related ADRs.

Although a few reports have focused on patients with cancer-related pain receiving intravenous morphine, the dose of intravenous morphine has been reported to vary (continuous $0.5-30 \mathrm{mg} / \mathrm{h}$ or intermittent $15-180 \mathrm{mg} /$ day) [12-14]. In patients with end-stage $\mathrm{HF}$, a relatively low dose may be effective because the purpose of the morphine is to control dyspnea/breathlessness and noncancer pain/distress [5, 17, 18]. Two previous studies in Japanese patients with endstage HF reported doses of continuously infused morphine, including intravenous and subcutaneous infusions, ranging from 6 to $12 \mathrm{mg} /$ day $(0.25-0.5 \mathrm{mg} / \mathrm{h})$ in one study, with a median of $7.5 \mathrm{mg} /$ day $(0.3 \mathrm{mg} / \mathrm{h})$ in the other study $[18,19]$. In our study, the maintenance dose (median $0.4 \mathrm{mg} / \mathrm{h}$ [range 0.1-1.6]) was similar to those in previous reports involving patients with end-stage HF. The incidence of morphinerelated ADRs was also comparable to that in a previous 
Table 2 Comparison of morphine-related adverse reactions

\begin{tabular}{|c|c|c|c|c|c|c|c|c|c|c|c|}
\hline \multirow[t]{2}{*}{ Adverse reaction } & & \multirow[t]{2}{*}{$n$} & \multicolumn{3}{|c|}{ Maintenance dose $(\mathrm{mg} / \mathrm{h})$} & \multicolumn{3}{|c|}{ Duration (days) } & \multicolumn{3}{|c|}{$\mathrm{eGFR}\left(\mathrm{ml} / \mathrm{min} / 1.73 \mathrm{~m}^{2}\right)$} \\
\hline & & & Median & Range & $p$ value & Median & Range & $p$ value & Median & Range & $p$ value \\
\hline \multirow[t]{2}{*}{ All adverse reactions } & Yes & 14 & 0.4 & $0.2-1.6$ & 0.89 & 4 & $1-22$ & 0.83 & 16 & $9-48$ & 0.012 \\
\hline & No & 24 & 0.4 & $0.1-1.3$ & & 5 & $1-52$ & & 41 & $8-133$ & \\
\hline \multirow[t]{2}{*}{ Nausea/vomiting } & Yes & 5 & 0.4 & $0.2-0.8$ & 0.73 & 3 & $2-4$ & 0.085 & 27 & $9-48$ & 0.64 \\
\hline & No & 33 & 0.4 & $0.1-1.6$ & & 5 & $1-52$ & & 28 & $8-133$ & \\
\hline \multirow[t]{2}{*}{ Respiratory depression } & Yes & 3 & 0.4 & $0.1-0.4$ & 0.89 & 4 & $1-6$ & 0.53 & 17 & $13-28$ & 0.26 \\
\hline & No & 35 & 0.4 & $0.1-1.6$ & & 4 & $1-52$ & & 32 & $8-133$ & \\
\hline \multirow[t]{2}{*}{ Drowsiness } & Yes & 13 & 0.4 & $0.2-1.6$ & 0.68 & 4 & $1-52$ & 0.41 & 16 & $9-39$ & 0.003 \\
\hline & No & 25 & 0.4 & $0.1-1.3$ & & 4 & $1-21$ & & 47 & $8-133$ & \\
\hline
\end{tabular}

$e G F R$ estimated glomerular filtration rate

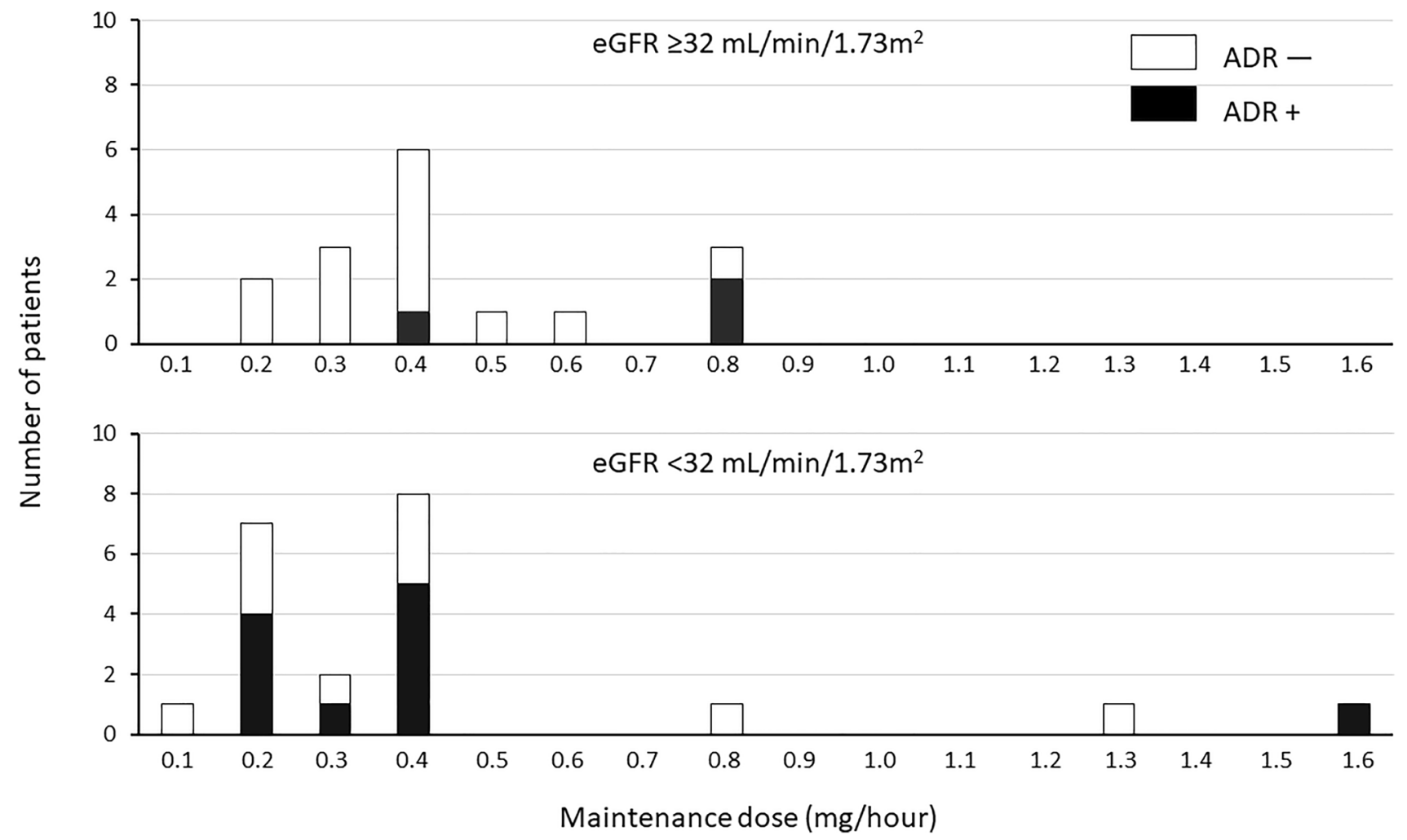

Fig. 2 Frequency of patients experiencing morphine-related adverse drug reactions (ADRs) according to the maintenance dose in patients with estimated glomerular filtration rate (eGFR) of $\geq 32$ and $<32 \mathrm{~mL} / \mathrm{min} / 1.73 \mathrm{~m}^{2}$

report involving patients with end-stage HF receiving oral or intravenous/subcutaneous morphine (approximately 30\%) [19].

In our study, drowsiness was the most common morphinerelated ADR. In patients with cancer-related pain treated with morphine, which is generally administered orally, the incidence of drowsiness ranges from 3 to $88 \%$ [20]. Previous reports in patients with end-stage HF showed that adverse central nervous system effects such as somnolence and delirium were most common among morphine-related ADRs, even when a low dose of morphine was administered [18, 19]. These symptoms might be partially due to the presence of advanced HF-related symptoms, and morphine, even at a low dose, is likely to induce these symptoms in an end-oflife HF care setting.

The dose and treatment duration of morphine did not affect the occurrence of ADR. Because morphine is used before death in most patients with end-stage HF, the shortterm use of morphine (median 4 days) might mean that the cumulative dose of morphine has limited influence on the 
occurrence of ADRs. However, an eGFR $<32 \mathrm{~mL} / \mathrm{min} / 1.73$ $\mathrm{m}^{2}$ was significantly associated with the occurrence of morphine-related ADRs. A recent large cohort study reported that the incidence of ADRs was approximately twice as high in patients with eGFR $<30 \mathrm{~mL} / \mathrm{min} / 1.73 \mathrm{~m}^{2}$ than in patients with eGFR $\geq 30 \mathrm{~mL} / \mathrm{min} / 1.73 \mathrm{~m}^{2}$ and that most ADRs resulted from reduced renal clearance of drugs [21]. Morphine and its active metabolite M6G, which crosses the blood-brain barrier, are excreted by the kidneys [8]. In patients with advanced HF and renal dysfunction, renal clearance of both compounds may be reduced, leading to increased blood drug concentrations and the onset of ADRs. In our study, there was no difference in the initial dose of morphine between patients with an eGFR $<32 \mathrm{~mL} /$ $\mathrm{min} / 1.73 \mathrm{~m}^{2}$ and those with an eGFR $\geq 32 \mathrm{~mL} / \mathrm{min} / 1.73 \mathrm{~m}^{2}$ (median $0.4 \mathrm{mg} / \mathrm{h}$ [range $0.1-0.4$ ] vs. 0.4 [range $0.2-0.4$ ], respectively). A recent case report showed that the morphine-related ADRs drowsiness and respiratory depression resolved when the dose of intravenous morphine infusion was reduced from 0.5 to $0.2 \mathrm{mg} / \mathrm{h}$ in a Japanese patient with $\mathrm{HF}$ and renal failure receiving hemodialysis [22]. The lack of dose adjustment in patients with renal dysfunction might partially contribute to the occurrence of morphine-related ADRs. Dose adjustment (a decrease in the initial dose by $50 \%$ ) of the continuous morphine infusion can prevent ADRs in patients with end-stage HF and an eGFR $<32$ $\mathrm{mL} / \mathrm{min} / 1.73 \mathrm{~m}^{2}$.

Interestingly, ADR was not observed in seven patients receiving ACE inhibitors/ARBs in this study. The preventive effect of ACE inhibitors/ARBs on morphine-related ADRs is unknown. A recent experimental study reported that captopril enhanced morphine analgesia and prevented tolerance development in rats [23]; thus, there may be some interactions between ACE inhibitors/ARBs and morphine. Further investigation is needed to confirm this issue. Four patients received concomitant sedative drugs such as dexmedetomidine and midazolam with morphine. One patient treated with midazolam experienced respiratory depression after the start of continuous morphine, but the other three patients treated with dexmedetomidine did not experience morphine-related ADRs. Concomitant sedation with benzodiazepines might partially contribute to the development of morphine-related ADRs. Moreover, advances in pharmacogenetics have provided new insights into the morphine response. Opioid receptor mu 1 (OPRM) has been shown to alter mu-opioid receptor signaling and the response to M6G. Patients who are 118 A/A homozygotes (wild type) are reported to be good responders to morphine, whereas those who are $118 \mathrm{G} / \mathrm{G}$ homozygotes need more morphine to achieve a good response [24]. Another report showed that a patient with renal failure with OPRM $118 \mathrm{~A} / \mathrm{A}$ experienced pain relief but also drowsiness after the administration of morphine, whereas another patient with renal failure with
OPRM $118 \mathrm{G} / \mathrm{G}$ tolerated morphine well despite a high blood M6G concentration [25]. Pharmacogenetic differences may also affect the occurrences of ADRs in patients receiving morphine.

\subsection{Study Limitations}

This study has some limitations. First, it was a retrospective observational study. There was no established treatment protocol with regard to morphine infusion, and the dose was determined by physicians. ADRs other than the symptoms selected for assessment in this study were not fully evaluated. We could not completely differentiate morphine-related ADRs from HF symptoms because these symptoms overlap with HF symptoms. This was a single-center cohort study conducted at a university hospital. Our results are limited in their generalizability to the management of Japanese patients with end-stage HF. Second, we did not measure the blood concentrations of morphine and its active metabolites. The differences in pharmacokinetic profiles among patients and the contribution of those profiles to the occurrence of ADRs remains unknown. Third, we could not quantitatively assess the efficacy of morphine for the relief of dyspnea based on the chart review; however, in each case, the goal of eliminating the symptoms and distress in patients was achieved based on the clinical evaluation performed by physicians. Fourth, the number of subjects was small. Subgroup analyses could not be performed.

\section{Conclusions}

Our results indicated that $37 \%$ of patients with end-stage $\mathrm{HF}$ receiving continuous intravenous/subcutaneous morphine infusion experienced ADRs, especially drowsiness. A baseline eGFR $<32 \mathrm{~mL} / \mathrm{min} / 1.73 \mathrm{~m}^{2}$ was significantly associated with the occurrence of morphine-related ADRs.

Acknowledgements The authors thank Ms. Toshiko Konishi for their helpful comments.

\section{Declarations}

Funding This research received no grants from any funding agency in the public, commercial, or not-for-profit sectors.

Conflict of Interest Masayuki Gotou, Atsushi Suzuki, Tsuyoshi Shiga, Rumi Wakabayashi, Mayui Nakazawa, Noriko Kikuchi, and Nobuhisa Hagiwara have no conflicts of interest that are directly relevant to the content of this article.

Ethics Approval The protocol was approved by the Institutional Review Board of Tokyo Women's Medical University (5402) because of the retrospective nature of the study, and all the procedures being performed were part of routine care. 
Consent to Participate The requirement for written informed consent was waived because of the retrospective design.

Consent for Publication Not applicable.

Availability of Data and Materials The data that support the findings of this study are available from the corresponding author upon reasonable request.

\section{Code Availability Not applicable.}

Author Contributions AS and TS conceived of and designed the study. MG collected and organized the patient data from the patient files. MG and AS analyzed the data. RW, MN, and NK contributed to the interpretation of the data. TS was a major contributor in writing the manuscript. NH supervised the work. All authors read and approved the final manuscript.

Open Access This article is licensed under a Creative Commons Attribution-NonCommercial 4.0 International License, which permits any non-commercial use, sharing, adaptation, distribution and reproduction in any medium or format, as long as you give appropriate credit to the original author(s) and the source, provide a link to the Creative Commons licence, and indicate if changes were made. The images or other third party material in this article are included in the article's Creative Commons licence, unless indicated otherwise in a credit line to the material. If material is not included in the article's Creative Commons licence and your intended use is not permitted by statutory regulation or exceeds the permitted use, you will need to obtain permission directly from the copyright holder. To view a copy of this licence, visit http://creativecommons.org/licenses/by-nc/4.0/.

\section{References}

1. Fang JC, Ewald GA, Allen LA, Butler J, Westlake Canary CA, Colvin-Adams M, Dickinson MG, Levy P, Stough WG, Sweitzer NK, Teerlink JR, Whellan DJ, Albert NM, Krishnamani R, Rich MW, Walsh MN, Bonnell MR, Carson PE, Chan MC, Dries DL, Hernandez AF, Hershberger RE, Katz SD, Moore S, Rodgers JE, Rogers JG, Vest AR, Givertz MM, Heart Failure Society of America Guidelines Committee. Advanced (stage D) heart failure: a statement from the Heart Failure Society of America Guidelines Committee. J Card Fail. 2015; 21:519-34. https://doi.org/ 10.1016/j.cardfail.2015.04.013.

2. Tsutsui $\mathrm{H}$, Isobe $\mathbf{M}$, Ito $\mathrm{H}$, Ito $\mathrm{H}$, Okumura $\mathrm{K}$, Ono $\mathbf{M}$, Kitakaze M, Kinugawa K, Kihara Y, Goto Y, Komuro I, Saiki Y, Saito Y, Sakata Y, Sato N, Sawa Y, Shiose A, Shimizu W, Shimokawa H, Seino Y, Node K, Higo T, Hirayama A, Makaya M, Masuyama T, Murohara T, Momomura SI, Yano M, Yamazaki K, Yamamoto K, Yoshikawa T, Yoshimura M, Akiyama M, Anzai T, Ishihara S, Inomata T, Imamura T, Iwasaki YK, Ohtani T, Onishi K, Kasai T, Kato M, Kawai M, Kinugasa Y, Kinugawa S, Kuratani T, Kobayashi S, Sakata Y, Tanaka A, Toda K, Noda T, Nochioka K, Hatano M, Hidaka T, Fujino T, Makita S, Yamaguchi O, Ikeda U, Kimura T, Kohsaka S, Kosuge M, Yamagishi M, Yamashina A, Japanese Circulation Society and the Japanese Heart Failure Society Joint Working Group. JCS 2017/JHFS 2017 Guideline on diagnosis and treatment of acute and chronic heart failure-digest version. Circ J. 2019; 83:2084-184. https://doi.org/10.1253/circj. CJ-19-0342.

3. Anderson H, Ward C, Eardley A, Gomm SA, Connolly M, Coppinger T, Corgie D, Williams JL, Makin WP. The concerns of patients under palliative care and a heart failure clinic are not being met. Palliat Med. 2001;15:279-86. https://doi.org/10.1191/ 026921601678320269.

4. Hunt SA, Abraham WT, Chin MH, Feldman AM, Francis GS, Ganiats TG, Jessup M, Konstam MA, Mancini DM, Michl K, Oates JA, Rahko PS, Silver MA, Stevenson LW, Yancy CW. 2009 focused update incorporated into the ACC/AHA 2005 Guidelines for the Diagnosis and Management of Heart Failure in Adults: a report of the American College of Cardiology Foundation/American Heart Association Task Force on Practice Guidelines: developed in collaboration with the International Society for Heart and Lung Transplantation. Circulation. 2009;119:e391-479. https:// doi.org/10.1161/CIRCULATIONAHA.109.192065.

5. Johnson MJ, McDonagh TA, Harkness A, McKay SE, Dargie HJ. Morphine for the relief of breathlessness in patients with chronic heart failure-a pilot study. Eur J Heart Fail. 2002;4:753-6. https:// doi.org/10.1016/s1388-9842(02)00158-7.

6. Anzai T, Sato T, Fukumoto Y, Izumi C, Kizawa Y, Koga M, Nishimura K, Ohishi M, Sakashita A, Sakata Y, Shiga T, Takeishi Y, Yasuda S, Yamamoto K, Abe T, Akaho R, Hamatani Y, Hosoda H, Ishimori N, Kato M, Kinugasa Y, Kubozono T, Nagai T, Oishi S, Okada K, Shibata T, Suzuki A, Suzuki T, Takagi M, Takada Y, Tsuruga K, Yoshihisa A, Yumino D, Fukuda K, Kihara Y, Saito Y, Sawa Y, Tsutsui H, Kimura T, Japanese Circulation Society Joint Working Group. JCS/JHFS 2021 Statement on Palliative Care in Cardiovascular Diseases. Circ J. 2021; 85:695-757. https://doi. org/10.1253/circj.CJ-20-1127.

7. Glare P, Walsh D, Sheehan D. The adverse effects of morphine: a prospective survey of common symptoms during repeated dosing for chronic cancer pain. Am J Hosp Palliat Care. 2006;23:229-35. https://doi.org/10.1177/1049909106289068.

8. Dean M. Opioids in renal failure and dialysis patients. J Pain Symptom Manage. 2004;28:497-504. https://doi.org/10.1016/j. jpainsymman.2004.02.021.

9. Shiga T, Suzuki A, Haruta S, Mori F, Ota Y, Yagi M, Oka T, Tanaka H, Murasaki S, Yamauchi T, Katoh J, Hattori H, Kikuchi N, Watanabe E, Yamada Y, Haruki S, Kogure T, Suzuki T, Uetsuka Y, Hagiwara N; HIJ-HF II Investigators. Clinical characteristics of hospitalized heart failure patients with preserved, mid-range, and reduced ejection fractions in Japan. ESC Heart Fail. 2019; 6:475-86. https://doi.org/10.1002/ehf2.12418.

10. Matsuo S, Imai E, Horio M, Yasuda Y, Tomita K, Nitta K, Yamagata K, Tomino Y, Yokoyama H, Hishida A, Collaborators developing the Japanese equation for estimated GFR. Revised equations for estimated GFR from serum creatinine in Japan. Am J Kidney Dis. 2009; 53:982-92. https://doi.org/10.1053/j.ajkd.2008.12.034.

11. Common Terminology Criteria for Adverse Events (CTCAE) v5.0-JCOG. [CTCAE v5.0/MedDRA v20.1 (Japanese notation: MedDRA/J v24.0) compatible - March 5, 2021]. 2021. https:// www.jcog.jp/doctor/tool/CTCAEv5J_20210305_v24.0.pdf. Accessed 17 Apr 2021.

12. Citron ML, Johnston-Early A, Fossieck BE Jr, Krasnow SH, Franklin R, Spagnolo SV, Cohen MH. Safety and efficacy of continuous intravenous morphine for severe cancer pain. Am J Med. 1984;77:199-204. https://doi.org/10.1016/0002-9343(84) 90691-0.

13. Stuart GJ, Davey EB, Wight SE. Continuous intravenous morphine infusions for terminal pain control: a retrospective review. Drug Intell Clin Pharm. 1986;20:968-72. https://doi.org/10.1177/ 106002808602001211.

14. Harris JT, Suresh Kumar K, Rajagopal MR. Intravenous morphine for rapid control of severe cancer pain. Palliat Med. 2003;17:24856. https://doi.org/10.1191/0269216303pm695oa.

15. Evans RS, Lloyd JF, Stoddard GJ, Nebeker JR, Samore MH. Risk factors for adverse drug events: a 10-year analysis. Ann Pharmacother. 2005;39:1161-8. https://doi.org/10.1345/aph.1E642. 
16. Davies EA, O’Mahony MS. Adverse drug reactions in special populations - the elderly. Br J Clin Pharmacol. 2015;80:796-807. https://doi.org/10.1111/bcp.12596.

17. Johnson MJ, Cockayne S, Currow DC, Bell K, Hicks K, Fairhurst C, Gabe R, Torgerson D, Jefferson L, Oxberry S, Ghosh J, Hogg KJ, Murphy J, Allgar V, Cleland JGF, Clark AL. Oral modified release morphine for breathlessness in chronic heart failure: a randomized placebo-controlled trial. ESC Heart Fail. 2019;6:1149-60. https://doi.org/10.1002/ehf2.12498.

18. Murakami M. Opioids for relief of dyspnea immediately before death in patients with noncancer disease: a case series study. Am J Hosp Palliat Care. 2019;36:734-9. https://doi.org/10.1177/10499 09119832816.

19. Kawaguchi J, Hamatani Y, Hirayama A, Nishimura K, Nakai E, Nakamura E, Miyata M, Kawano Y, Takada Y, Anchi Y, Funabashi S, Kuroda K, Azechi M, Takahama H, Anzai T, Yasuda S, Kitaoka H, Izumi C. Experience of morphine therapy for refractory dyspnea as palliative care in advanced heart failure patients. J Cardiol. 2020;75:682-8. https://doi.org/10.1016/j.jjcc.2019.12. 015 .

20. Oosten AW, Oldenmenger WH, Mathijssen RH, van der Rijt CC. A systematic review of prospective studies reporting adverse events of commonly used opioids for cancer-related pain: a call for the use of standardized outcome measures. J Pain. 2015;16:93546. https://doi.org/10.1016/j.jpain.2015.05.006.
21. Laville SM, Gras-Champel V, Moragny J, Metzger M, Jacquelinet C, Combe C, Fouque D, Laville M, Frimat L, Robinson BM, Stengel B, Massy ZA, Liabeuf S. Chronic kidney disease-renal epidemiology and information network (CKD-REIN) Study Group. Adverse Drug Reactions in Patients with CKD. Clin J Am Soc Nephrol. 2020;15:1090-102. https://doi.org/10.2215/CJN.01030 120.

22. Ohmori T, Mizuno A, Kawai F, Oya K, Okamura T, Oishi S, Shibata T, Sakashita A, Kishi T, Kashiwagi H. Morphine use for heart failure patients with renal insufficiency. J Palliat Med. 2019;22:617-8. https://doi.org/10.1089/jpm.2019.0127.

23. Taskiran AS, Avci O. Effect of captopril, an angiotensin-converting enzyme inhibitor, on morphine analgesia and tolerance in rats, and elucidating the inflammation and endoplasmic reticulum stress pathway in this effect. Neurosci Lett. 2021;741:135504. https://doi.org/10.1016/j.neulet.2020.135504.

24. Ofoegbu A, Ettienne BE. Pharmacogenomics and morphine. J Clin Pharmacol. 2021. https://doi.org/10.1002/jcph.1873.

25. Lötsch J, Zimmermann M, Darimont J, Marx C, Dudziak R, Skarke C, Geisslinger G. Does the A118G polymorphism at the mu-opioid receptor gene protect against morphine-6-glucuronide toxicity? Anesthesiology. 2002;97:814-9. https://doi.org/10.1097/ 00000542-200210000-00011. 